\title{
Intimate Image Dissemination and Consent in a Digital Age: Perspectives from the Front Line
}

\author{
Olga Marques
}

\begin{abstract}
Media attention on nonconsensual intimate image dissemination has led to the relatively recent proliferation of academic research on the topic. This literature has focused on many areas including victimization and perpetration prevalence rates, coerced sexting, legal and/or criminal contexts, sexual violence in digital spaces, gendered constructions of blame and risk, and legal analysis of high-profile cases and legislation. Despite this research, several gaps exist, including a lack of empirical research with service providers. Informed by indepth interviews with 10 sexual violence frontline professionals in Southern Ontario (Canada), this chapter focuses on their perspectives of the additive role of technology. With respect to nonconsensual intimate image dissemination, technology acts as a digital "layer" that operates in addition to the commission of physical acts of sexual violence, and compounds the harms experienced by the victim by adding a virtual - and indelible - "permanent remembering" of the violence. Nuancing the contours of consent in a digital age, this chapter concludes by considering what consent means in a technological context.
\end{abstract}

Keywords: Nonconsensual intimate image dissemination; consent; permanent remembering; sexual violence; frontline workers; barriers to legal system

\section{Introduction}

Public outrage, particularly by women students, was garnered following reports that a revenge pornography website ${ }^{1}$ was targeting universities (Green, 2018). In

The Emerald International Handbook of Technology-Facilitated Violence and Abuse, 309-328

Copyright $(\odot) 2021$ Olga Marques

Published by Emerald Publishing Limited. This chapter is published under the Creative

Commons Attribution (CC BY 4.0) licence. Anyone may reproduce, distribute, translate and create derivative works of these chapters (for both commercial and non-commercial purposes), subject to full attribution to the original publication and authors. The full terms of this licence may be seen at http://creativecommons.org/licences/by/4.0/legalcode.

doi:10.1108/978-1-83982-848-520211022 
2018, the website, which had entries for several Canadian universities in the Greater Toronto Area (GTA), stated that it specialized in the "trade, sale, and distribution of sexually explicit images and videos of women, without their consent." ${ }^{2}$ Users could view images and videos, leave comments, and request more images of particular women, offering money in exchange. Images were shared through a temporary file-storing service that deleted personal information, such as IP addresses, 48 hours after uploading. In April 2018, after Dutch police shut down the site (Liptak, 2018), reader comments on news message boards as well as social media responses were polarized by those lauding police efforts, and those blaming the women themselves. Most telling among these responses were those that suggested the futility of shutting down such websites, including a reader comment posted to the Liptak (2018) news report by @thewhitesand that stated: "One door closes, another opens. [Redacted] will resurface under a new name in no time," (April 29, 2018), as well as a single (and since deleted) tweet by @ satancow, the only tweet ever posted by this account at the time: "\#[redacted] \#youcannotwin You may stop one, but will only give rise to another. Good luck stopping us all" (May 15, 2018). The fact that a website focused on posting nude images of women without their consent or knowledge was able to exist and be supported solidifies the urgency of further understanding the harms and implications of nonconsensual intimate image dissemination.

Extant media attention to nonconsensual intimate image dissemination, often colloquially and problematically referred to as "revenge pornography" (see e.g., McGlynn, Rackley, \& Houghton, 2017; Powell, Henry, \& Flynn, 2018), has led to the relatively recent emergence of academic research on the topic. Existing research has largely focused on ascertaining victimization and perpetration prevalence rates (e.g., Branch, Hilinski-Rosick, Johnson, \& Solano, 2017; Eaton, Jacobs, \& Ruvalcaba, 2018; Henry et al., 2020; Powell, Henry, Flynn, \& Scott, 2019; Powell, Scott, Flynn, \& Henry, 2020), coerced sexting (e.g., Lee \& Crofts, 2015; Wolak, Finkelhor, Walsh, \& Treitman, 2018), the legal and/or criminal context (Bloom, 2014; Flynn \& Henry, 2019; Slane, 2013; Slane \& Langlois, 2018), sexual violence in digital spaces (e.g., Fairbairn, 2015; Powell \& Henry, 2017), gendered constructions of blame and risk (e.g., Karaian, 2014; Starr \& Lavis, 2018), and legal analysis of specific high-profile cases and legislation (e.g., Henry, Flynn, \& Powell, 2019; Penney, 2016). Despite this, several research gaps exist. For instance, empirical research focusing exclusively on the experiences of survivors is lacking (see Bates, 2017; Henry et al., 2020; McGlynn et al., 2019, 2020; Walker \& Sleath, 2017 for exceptions). While much research has focused on prevalence rates of nonconsensual intimate image sharing, few have attended to the motivations of perpetrators (see Henry et al., 2020; Powell et al., 2019; Walker \& Sleath, 2017 for exceptions). In addition, there exists a lack of empirical research on nonconsensual intimate image dissemination, which focuses on the perspectives of sexual violence service providers (see Henry, Flynn, \& Powell, 2018 for exception).

This chapter seeks to contribute to the existing knowledge on the issue of nonconsensual intimate image dissemination by focusing on professionals' perspectives and understandings of the additive role that technology plays in the harms and impacts of sexual violence. This chapter focuses on intimate image/ 
video dissemination as a digital "layer" that operates in addition to the commission of physical acts of sexual violence, and which compounds the harms experienced by the victim by adding a virtual - and indelible - "permanent remembering" (Mayer-Schönberger, 2009, p. 127) of the violence (see also Henry et al., 2020; McGlynn et al., 2019, 2020). The permanency of images, as well as the trauma associated with the "threat" that images/videos can be released at any time in the future, without warning, becomes part of the crisis that frontline professionals must address in their responses. This chapter concludes by considering what consent means in a technological context. Here, I seek to nuance the contours of consent in a digital age, extending beyond the theoretical frameworks of cyberbullying or risk management proffered in existing literature, and engage with the discussions highlighted by the research participants as they grapple with this question.

\section{Research Overview}

In-depth, semi-structured qualitative interviews were conducted with 10 professionals working in various capacities employed in organizations that provide counseling and support services to women victims of sexual assault and violence generally, in a large suburban regional area in Southern Ontario, Canada. ${ }^{3}$ These professionals included executive directors, program managers, counsellors, and nurses. Interviews were conducted in the respondents' private offices, recorded, and transcribed. Interview length ranged from 35 minutes to 1 hour.

The overall purpose of this research was twofold. First, to discover, describe, and understand the perspectives of frontline sexual violence support professionals on the topic of nonconsensual intimate image dissemination. Second, to explore generalized accounts of the contexts and situations where this act/crime is perpetrated, how client disclosures are navigated, as well as the supports/ counseling currently available and offered. The interview questions were designed to address these research purposes.

The research itself focused on organizations, and not what individual professionals may or may not do in individual practice. No identifying information about clients was shared, and the following statement was highlighted in the Letter of Informed Consent: "Participants are responsible for ensuring that anything they discuss within the interviews does not violate the terms of their licensing and confidentiality which must be maintained in their practice." In order to further protect the identity of clients, all identifying organizational information was anonymized, or redacted and replaced with general descriptors. In this chapter, only the generalized job titles of the interview respondents (e.g., manager) are used.

While victimization research continues to find high overall incidence rates of sexual violence, it remains one of the most underreported of the violent crimes (Beres, Crow, \& Gotell, 2009; Chon, 2014; Patterson, Greeson, \& Campbell, 2009). There exists much research on barriers to formal police reporting, including feelings of shame, guilt, and/or embarrassment; fear of not being believed; perceived responsibility for the assault; and notions that the victimization did not reflect 
stereotypical characterizations of sexual assault (cf. Chon, 2014; Flynn, 2015; Patterson et al., 2009; Sable, Danis, Mauzy, \& Gallagher, 2006). Of course, while individuals who experience unwanted sexual violence may not be reporting to the police, research suggests they may be disclosing to and seeking out counseling and emotional support from other service providers, such as community clinics, private mental health professionals, or speciality agencies such as rape crisis centers (Campbell, 2006). In Ontario, Canada, the 42 sexual assault centers combined receive an estimated 50,000 crisis calls annually (Rushowy, 2020). Research on sexual violence support services as well as disclosure and reporting rates and/or barriers are important to understanding the broader context in which victimization by nonconsensual intimate image dissemination is situated. McGlynn et al. (2017) argue that this type of sexual violence "should be understood as just one form of a range of gendered, sexualized forms of abuse which have common characteristics forming what we have conceptualized as the 'continuum of image-based sexual abuse" (p. 26).

Questioning whether or not independent rape crisis centers play a unique role in their communities for survivors of sexual violence and the community at large, O'Sullivan and Carlton (2001) argue that they do:

...independent centres were the only ones that advanced inclusive definitions of sexual assault, incorporated cultural concerns in assessing their services and outreach, used volunteers as community educators, and targeted community education to young people and males. Second, embedded centres, particularly ones within domestic violence programs, seem to underserve sexual assault victims in the community. [...] The staff members and volunteers of the independent centres focus solely on sexual assault. They read the sexual assault literature. Their clients have all been affected by sexual assault. When they speak at schools, community gatherings, and in-service training sessions, they talk about sexual assault. They observe how people respond to sexual violence, and they reflect on what they see and hear. They try to be more inclusive and to understand variations in their client population, that is, who is likely to never contact them, who calls only once, and who uses and benefits from available services (p. 356).

Given their position within society and research indicating that community service providers are more likely to hear disclosures of sexual violence than formal reporting institutions like the police, it is important to understand how frontline service, support, and counseling providers are navigating the new virtual terrain. This is particularly so, given the types of challenges this can raise, considering that "nonconsensual pornography did not exist on such a broad scale even five years ago" (Bates, 2017, p. 25), and images can initially be obtained through consensual sharing between parties with the expectation they will not be distributed outside those parameters (Bates, 2017). 
This chapter relies heavily on Mayer-Schönberger's (2009) concept of "permanent remembering," a term introduced in the book Delete: The Virtue of Forgetting in the Digital Age. Tracing the history of memory - the basis of human knowledge - Mayer-Schönberger (2009) questions the implications of permanent digital memory. While critiques might suggest that a key benefit of digital technology is that it compensates for the inability of the human mind to remember everything, Mayer-Schönberger (2009) argues that this benefit should not be at the expense of the valuable capacity to forget. The consequences, it is argued, of not being able to leave our pasts behind, is a more unforgiving future. In the same way that Jeremy Bentham conceptualized prison as an all-seeing and ever-present panopticon where prisoners are watched, it can be argued that this panopticon now extends to society more broadly across time and cyberspace. As MayerSchönberger (2009, p. 127) asserts, "At the interface of power and time, permanent remembering creates the specter of a spatial and temporal panopticon, in which everybody may constantly be tempted to self-censor." As a result of the knowledge of the permanency of digital traces, risk management language is deployed cautioning us to be cognizant of our digital footprint, as well as about what, where, and for whom, we post virtually.

While Mayer-Schönberger (2009) does not speak specifically about sexual violence or nonconsensual intimate image dissemination or the ramifications of "permanent remembering" for victims of these crimes, these ideas can - and should - be extended to this area (see Henry et al., 2020; McGlynn et al., 2019). The questions posed of digital memory, the inability to forget, and the selfpolicing and censorship surrounding this virtual panopticon provide an analytic entry point to contextualize the accounts of sexual violence support and/or counseling professionals, and situate the experiences of those who seek support after having their intimate images and videos nonconsensually disseminated.

\section{Digital Layer Lends to "Permanent Remembering"}

The sexual violence professionals interviewed for this study had much to say regarding the ways in which victimization by nonconsensual intimate image dissemination is disclosed within their respective organizations. The contexts in which this victimization occurs varied. Some participants described examples where images were initially shared consensually within the confines of a relationship then subsequently released. Others mentioned images being "stolen" from devices or manipulated. Some participants reported victims were coerced to take images, and others described acts of sexual violence being recorded and disseminated. However, what was evident throughout the interviews was the additional layer of trauma, support, and healing that this type of victimization necessitated. As one nurse described:

I don't know if there is a lot of education around what the ramifications are, and when it is no longer a loving relationship or fun anymore. And we do know victims when they found out later that pictures where taken ... maybe a picture was shown to 


\section{Olga Marques}

them, or their friend sends them a picture saying "is this you?" And they didn't even know a picture was taken because they were sleeping. Or it can be a consensual relationship, but the person took a picture of them sleeping. The picture was not taken under consent, and then they are feeling violated.

Since nonconsensual intimate image dissemination is technologically facilitated and exists through digital spaces, this poses an additional layer that counsellors and support providers must navigate. Throughout the interviews, all respondents spoke to the permanency of these images and how part of their service or counseling practice related to working through associated feelings of (at least partial) self-responsibilization, as well as the practicalities of dealing with the virtual world. All respondents reported that clients had different sorts of questions and concerns related to being victimized in this way. For instance, an executive director stated:

... they are wanting to address the feelings associated with that. Feelings of powerlessness, of shame, of feeling victimized sexually, sexually interfered with or violence in some way. Even though it is virtual as opposed to physical. Dealing with the practicalities of "What can I do?" "What are my options?" With youth, when they have shared those images, they are not necessarily wanting to get that person into trouble. Or maybe they are, but they aren't because of the implications of that for them socially. So it's not always super easy to navigate.

Mayer-Schönberger (2009, p. 127) writes that:

[C]omprehensive digital remembering collapses history, impairing our judgement and our capacity to act in time. It denies us humans the chance to evolve, develop, and learn, leaving us helplessly oscillating between two equally troubling options: a permanent past and an ignorant present.

This is a poignant statement when related to the effects of nonconsensual intimate image dissemination. The pictures or videos circulating virtually are permanent vestiges of broken trust and acts of violence. While therapeutic support, and even legal intervention, may assist in an individual's ability to cope, survive, and thrive post physical acts of sexual violence, the permanency associated with digital spaces results in a post that is ambiguous. Is there even a post when images and videos are virtual? As a victim/survivor in McGlynn et al.'s (2019, p. 7) study of 60 victims across Australia, New Zealand, and the United Kingdom observed:

Maybe you could have something happen to you that was traumatic, but you don't have to necessarily feel like you're 
defined by it for the rest of your life. But with this, there's such a level of permanence which affects everything ... especially if it's impossible now to take photos down, especially if it's impossible to stop the dissemination of the images ... There will never be a day in my entire lifetime that all of the images of me could ever be deleted.

This space of uncertainty is also captured in my interviews by a counselor who claimed:

... the impact of something like this cannot be just devastating, but can be lifelong. This is the kind of thing that one potentially carries with them for the rest of their lives. And if you add to that the additional fear that other people will find out, and the image of them is floating out there in cyber world, that's also terrifying. Because you are waiting for the "ball to drop" sort of thing. ...The impact of that alone is quite devastating, because anybody can find out. So now they are trying to deal with something that has happened to them, while also simultaneously having been exposed sort of to the world.

This reiterates Mayer-Schönberger (2009) statement that we become "helpless" to a past that is permanent and to a present - and even a future - that we cannot anticipate.

Within the context of nonconsensual intimate image dissemination, the sexual violence does not cease. The threat of revictimization by the same act will always be present. As one executive director observed:

...you are not just dealing with the original assault, you are also dealing with all of these other fears and shame and, you know, everything that can come out of that. It doesn't go away. When something is on the internet or shared on social media, and you haven't put it up there, you don't have the control to take it down. It is there forever. How do you deal with that? How do you deal with the possibility of it coming up over and over in your life? It's hard to get closure that way.

As the popular idiom "forgive and forget" suggests, in order to make the decision to move past any given act, incident, or event that caused harm, a modicum of not remembering is required. This does not mean that harms are excused or forgotten, nor does it mean that the individual is in denial, but rather that a decision is made to work through, and potentially let go of feelings of resentment, so that the traumatic event does not become central to one's identity, or poorly incorporated into one's broader autobiographical memory (cf. Burkell, 2016; Ehlers \& Clark, 2000). Therapeutically working through associations that trigger memories of traumatic events and/or induce emotional responses, and 
coming up with coping strategies is often part of professional practice; however, the virtual nature of nonconsensual intimate image dissemination poses challenges in identifying these associations. As a nurse described to me:

It's very difficult because there is no, there is no reconciliation for that. How do you fix that? You can't. So it is then something that the victims have to think about for the rest of their lives. That there are images out there that they have no control over, and there is no way of eliminating them forever.

Mayer-Schönberger (2009) highlights the important role that forgetting has played throughout history, indicating that "[s]ince the beginning of time, for us humans, forgetting has been the norm and remembering the exception" (p. 2). Digital and virtual technology has turned this dynamic around, in that "forgetting has become the exception, and remembering the default" (p. 2). Providing examples of adults who have suffered repercussions (e.g., job loss, public shaming) when memories resurfaced online from incidents or mistakes of their youth, Mayer-Schönberger (2009, p. 3) asks, "Do we want a future that is forever unforgiving because it is unforgetting?" The response to this question may vary depending on the group or topic in question, particularly during current times characterized by the hashtags \#cancelculture or \#calloutculture ${ }^{4}$ (Romano, 2019). But it important to question: What can the future look like for individuals whose victimization is indelibly etched in the virtual world?

\section{Compounding of Trauma}

Across the interviews, a key theme emerged surrounding the potential consequences of the digital traces of victimization that are left behind and how these digital traces serve to compound the trauma that is already being experienced. While the previous section spoke to the digital layer of trauma, and how acts of sexual violence experienced physically are also re-experienced virtually, the additive trauma and/or potential consequences incurred as a result of having intimate images disseminated nonconsensually online extend well beyond this.

Considerations were made within the interviews to consequences to personal safety, potential judgment, as well as impacts to future job opportunities. As one executive director described:

It's hard enough that they're dealing with the trauma, after the sexual assault, but then dealing with the possibility of their image being shared with god knows who, you know, whether it is in their own country, in another country, are people going to see it? What effect is that going to have on you down the road? What assumptions might be made about you because of that? Are there people that are going to judge you, you know, who may not realize that this was not consensual? ... Just dealing with those initial fears. Fears around your own security, your own safety. 
What if somebody sees it and then they track her down? Being approached on social media. Would somebody try to reach out to her friends? Her family? Share information about this?

Another executive director similarly reflected:

It's not just the consequence of "well this person betrayed my trust," it's the trauma that you know victims or survivors of this endure. It's ongoing. This is now out in the world, and we don't know who's hand it's in. And we don't know where it is. And if you are looking for a job later on, and how this would perpetually impact your life. And that's a deep trauma that we have to constantly process with the client that we support. In terms of how they are feeling, and the embarrassment, the shame; there's so many therapeutic pieces that needs to be addressed.

That virtual spaces and digital memory offers a permanent and - for corporations, governments, and even law enforcement - a "usable" record of any given individual's deeds, misdeeds, actions, opinions, preferences, and so forth, is something that warrants much consideration. Individuals and societies will be altered as we move toward a lived reality where all of our digital transactions leave permanent digital traces; a dystopian future where our digital pasts may constrain our presents (Mayer-Schönberger, 2009). While some may neglect to grasp the scope of the issue of "permanent remembering," others may cling to the notion that they have "nothing to hide," and only those who contravened against societal norms will be affected. The public vitriol, shaming, and threats against Melissa Petro, ${ }^{5}$ for instance, and the subsequent loss of her teaching job after she wrote an op-ed about her brief time as a sex worker when she was 19, evinces that we must seriously consider what digital recall means for our lives. Petro (2017) continues to write that years after the publication of this op-ed, and despite being employed in many other fields, her work in the sex industry continues to surface virtually as her main identifier.

Morality, value, and worth continue to be tied to women's sexual passivity, while women who are actively sexual, particularly in nonsocially normative ways, are slut-shamed, victim-blamed, and responsibilized for any harms incurred (Marques \& Rinaldi, 2020). This suggests there are particular gendered realities and consequences to "permanent remembering" that must be considered.

Digital memory creates an illusion that we know someone's character, denies the possibility of change, and stymies decision-making and critical thought, as we have somehow come to believe that digital records are comprehensive accounts and complete. We have media reports of the impacts of digital memory for individuals who actively either posted accounts, videos, or images online, or at the very least, actively and consensually engaged in the acts or words depicted. However, we must reflect upon the impacts for individuals who have had images or videos nonconsensually disseminated - particularly in the case of intimate images and/or videos of women and teenage girls. 
Research exists on victim-blaming and rape myth acceptance generally, which serves to both responsibilize female victims for sexual violence incurred against them and minimize the realities of the scope of sexual violence (cf. Bailey, 2015; Edwards, Turchik, Dardis, Reynolds, \& Gidycz, 2011). As a result of rape myth acceptance, we are seeing calls for teenage girls and women to just not take intimate images and/or videos because, as Starr and Lavis (2018) indicate, "a victim of revenge porn may be viewed as responsible for taking and sending an image to someone in the first place" (p. 428; see also, Henry et al., 2019; Powell et al., 2018, 2020). It is without a doubt that the digital ways in which we are engaging with sexuality and sexual practice, as well as the virtual nature of the nonconsensual intimate image dissemination, pose interesting questions related to consent and what consent looks like in a technological context, which I explore below.

\section{Consent in the Technological Context}

Consent is the defining criteria when measuring what constitutes sexual violence within law, research, and interpersonal interactions (Burgin \& Flynn, 2019; Humphreys, 2007). However, there exists much conversation within the literature about what consent means, and what it can mean when decontextualized from conversations about hetero-patriarchal constructions of normative - and thus good and moral - sexual practice; the pleasures of sex and not just its dangers and consequences; and the shackles of constructs such as virginity, purity, and women's marital duty (Marques \& Rinaldi, 2020). This is all to suggest that while definitions of sexual consent are inscribed by law (for example, s. 273.1(1) of the Criminal Code of Canada) and guidelines for organizations with respect to collection and disclosure of personal information in a privacy context exist (for example, Office of the Privacy Commissioner of Canada, 2018), in interpersonal and relational practice, consent is much more nuanced.

While much scholarly and activist attention has advocated for affirmative consent - the knowing and voluntary assent to sexual activity throughout all stages of a sexual interaction, also known as the "enthusiastic yes" - much medialed conversation has been leveled against its "plain unworkability" (see for instance, McArdle, 2019). For example, Burgin and Flynn (2019) found that in practice, gendered narratives of implied consent - a perpetrator's subjective interpretation of a woman's ordinary behavior as indicative of her consent to sex - endure in sexual assault trials. It is no wonder that consent, particularly consent within the context of digital technology, was a significant topic of discussion during the interviews.

All research participants had much to say with respect to consent, how the contours of consent - what it is, what it means, and how it is articulated become more malleable and unclear when an act of sexual violence takes places virtually, and when, in nonconsensual intimate image dissemination, the initial image may have been shared consensually. Within the context of taken and subsequently shared pictures and videos, the meaning of consent and the 
revocation of consent become blurred. These nuances are captured by the following counselor's comments:

What is consent and do you waive consent when you send a photo? Like that's something that could be part of an act, is that consent waived? Is that something people need to know about? But again, that still should not give the right to someone to share it. But that risk is always there. And even if that individual doesn't share it, something can get stuck in the communication, in the middle. So it's not always necessarily the person you sent it to that did it, but someone that was in between that line of technology that got access to it.

A nurse similarly claimed:

If you don't really understand what your actions are, then you are really not in a position to give consent. And if you don't understand the risks of taking nude pictures of yourself and sending them out, then you are not really consenting to it, even though you are doing it. Even though consent is fluid, you can consent one minute and not the next. You can stop the sex act in the middle of it if you don't like it or if it's making you uncomfortable. But, once that send button is done on those pictures, you can't rescind your consent. And even if you do, it doesn't really matter, it's gone. It's out there. So it doesn't really matter what you consent to or not. You might have regrets the next day, or 30 friends point fingers at you and laugh, it's too late now to consent.

All participants raised the notion that consent in a technological context must extend to the potential foreseen and unforeseen consequences of the digital social sphere. In other words, consent does not just begin and end with taking an image and sharing it, but to the digital memory of those images. As a program manager described:

I don't think that young people understand that just because they have an image that other people should be able to share it. I feel like they don't understand what consent even means. That consent is a clear "yeah, I am putting this out there to share." And that even if you are sharing with your group of friends who you approved, doesn't mean that they should be able to share that with their friends, and with their friends. I don't think they understand that. I just don't think that young people even always understand what consent means. That they have the right to clearly say "yes" or "no" for anything want, and it is not just for physical acts, but acts that happen through technology. 
There is no denying that many of us live at least part of our lives on online platforms and use technology to facilitate sharing and communication within relationships. For youth, the digitization of their lives and experiences has always existed and is "normal." As a result, many interview participants - especially those who worked with youth - spoke about the challenges of teaching youth that online spaces are neither "safe" nor private to their own social worlds. For instance, a counselor observed:

I think the internet can be a very scary place and I am not too sure if enough teaching is being done around what is safe and what isn't safe. What can be posted and what shouldn't be posted. I think the innocence is that, you know, I can send my boyfriend this picture and it goes to my boyfriend. And as soon as there is that falling out, or power and control concerns come into play, and now it gets sent forward to whoever it may be. So videos, anything, and not realizing what the final outcome could look like just from sending a picture, or a message, or a video.

When describing consent, several participants were clear that we should be careful to not allow fears of digital memory to inculcate victim-blaming through discourses of risk management, or bring back regressive and sex-negative ideas about "appropriate" sexual conduct, especially appropriate sexual conduct for women and teenage girls. Corporeal agency still exists. Instead, we should attend to better educating ourselves as to what consent is, what consent means, and to the realities of lack of ownership over redistribution and future dissemination once content is shared digitally. This is reflected in this executive director's comments:

It's your right to share your pictures, your body to who you consent to do that to, and that doesn't give them the right to share it once it's their possession. But on the other side, once you give it to someone, you have no control about what they did with it, right? ... Educating young people about the nuances of consent. I think they are learning the wrong information. They are learning "yes means yes" and "no means no," and that's not really the true definition of consent. It can't be given under pressure, has to be ongoing, there are so many elements. I think young people need to understand what could happen if they send this to someone. That it could possibly be sent out. Without blaming them, without making them feel like it's their fault. But that a potential consequence of sharing, is that it is no longer under your control. It is in the world, and it could go into other people's hands that you didn't intend it to go to. 
While research and laws are attempting to keep pace with cyber-criminality and cyber-victimization, it is important to ensure that individuals engaging in their regular everyday lives are considered. This can be seen in research that being a perpetrator or victim of nonconsensual intimate image dissemination is outside of some people's thought processes. Rather, they are focused on expressing their sexuality and engaging relationally with others using digital tools, and in accordance with social constructions of appropriately gendered sexual expressions, roles, and expectations (Lee \& Crofts, 2015; Marques \& Rinaldi, 2020). More nuanced understandings of consent, what it means, and what it looks like are required - even more so when applied to the digital world.

\section{The Search for Solutions}

In accounting for individual consequences as a result of digital remembering (e.g., individuals who failed to get hired or were terminated when records of their past emerged online), historically tracing the history of human forgetting, and documenting the rise of technologies that allow for "permanent remembering," Mayer-Schönberger (2009) outlines six potential solutions to the problem. Some of these draw on digital rights management, privacy laws, and the passage - and enforcement - of regulatory and legal measures. One solution that is a common fixture in current online risk management strategies is digital abstinence. Digital abstinence suggests that individuals themselves play a central role in the compilation of their own digital image. Mayer-Schönberger (2009, p. 129) argues, "If one abstains from putting personal information online, one does not have to fear the consequences of an enduring digital memory - neither loss of control and power over information, nor being exposed to the digital panopticon or impaired reasoning."

To those well versed in sexual violence and rape myth acceptance literature, digital abstinence may sound familiar to the "she was walking at night by herself," "she is promiscuous," and "she was asking to be raped in that outfit" statements that evince victim-blaming rhetoric (see also, Flynn, 2015). If you do not want to be sexually victimized, just do not allow yourself to be victimized. If you do not want people to see your intimate images, just do not take them. Anything short of this abstinence renders you, as this rhetoric suggests, responsibilized and culpable (Powell et al., 2013, 2018). Of course, digital abstinence or victim-blaming rhetoric fails to account for how relationships have been technologized, relieves the onus of responsibility on the person who perpetrated the harm, and ignores that disseminated intimate images and videos may not have always been initially created in contexts of full consent (see Henry et al., 2020; Powell et al., 2020). As noted previously, Mayer-Schönberger (2009) is not writing specifically about violence, so the six potential solutions or responses outlined do not consider the impacts to victims of digitally perpetrated violence. However, Mayer-Schönberger (2009) also does not advocate digital abstinence (which is virtually impossible in current Western societies), nor to the other solutions 
outlined. Instead, the solution he proposes is to impose expiration dates on every single piece of information that is online - from emails, search terms, online purchase histories, pictures, to files on our hard drives. While this does not yet exist, he calls for the creation of simple interfaces to allow the user to specify what the data expiry date should be. While an analysis of this proposed solution is beyond the scope of this chapter, it begs the importance of working toward creative solutions that consider the impacts on victims of digitally perpetrated violence and do not focus solely on more laws and more regulations which do not serve to address the social contexts in which gender-based sexual violence arises and persists.

On March 10, 2015, the Protecting Canadians from Online Crime Act amended the Criminal Code of Canada. Included provisions are: (1) making criminal the nonconsensual distribution of intimate images, (2) empowering courts to order the removal of such images from the internet, (3) permitting the forfeiture of the devices used in the commission of the offense, and (4 reimbursing victims for costs incurred as a result of removing the images from the internet and elsewhere (Government of Canada, 2015). Despite the fact that it is been five years since the sharing of intimate images or videos without consent became a crime in Canada, police continue to receive thousands of complaints from individuals whose images have been posted or circulated (Allen, 2019). This suggests a disconnect between rendering an act criminal, its policing of it, lived experiences surrounding the role of digital technologies in sexual relationships, as well as broader public understandings of sexual harm and sexual privacy. This is to say that disclosures of nonconsensual intimate image dissemination will likely also increase to community support services and specialized rape crisis centers. Given that sexual violence offenses are among the least formally reported (Beres et al., 2009; Chon, 2014; Patterson et al., 2009), and when they are, existing research dictates experiences of revictimization or inadequate law enforcement response (cf. Chon, 2014; Flynn, 2015; Patterson et al., 2009; Sable et al., 2006), it is likely that these community and specialized supports are more likely to hear about these offenses. Attending to the practicalities of what such supports should look like, and what types of clinical or therapeutic strategies are the most efficacious in attending to the various issues and concerns associated with being victimized in this manner, should be a central focus for community service providers.

While Mayer-Schönberger (2009) does not write specifically about sexual or gender-based violence, extending his analysis to this area forces us to ask what the impacts of "permanent remembering" might be for those whose sexual victimization was in whole, or in part, facilitated digitally and disseminated virtually. As more people continue to engage with technology to facilitate communication and engage with others, a more cogent analysis of the impacts of the permanence of digital memory and the inability to forget is necessary. Such analysis must extend beyond debates over privacy in cyberspace or even cyberbullying. To be clear, nonconsensual intimate image dissemination is not only an issue of (sexual) privacy or bullying (through coercion or manipulation), although it can comprise both these types of harm. Above all, however, it is an issue of violence - more specifically, gender-based violence (McGlynn et al., 2017). Attending to the 
gendered component of sexual violence, particularly the gendered nature of nonconsensual intimate image dissemination, is also of central concern, however challenging. As Beres (2009, p. 159) notes:

At a policy and discursive level, we are witnessing the decontextualization of "crime" from social conditions and power relations that contribute to the widespread problem of sexual violence. While committed to "a get tough on crime agenda," the Harper Conservative government cut the budget of Status of Women Canada by $40 \%$, removed the word "equality" from its mandate and fundamentally altered the funding criteria for women's organizations, making research and activities related to activism ineligible for funding.

Research suggests that nonconsensual dissemination of intimate images for the purposes of revenge occurs across heterosexual and same-sex couples is perpetrated by both males and females, and includes both males and females as its targets (Starr \& Lavis, 2018). Despite this, we cannot discount the compendium of literature that speaks to how sexual violence disproportionately affects girls and women in scope, impact, and societal consequences, as a result of gendered hierarchies, social locations, and role expectations (Henry et al., 2020; McGlynn et al., 2017). Addressing the problems and challenges of the virtual world - and potential solutions - necessitates an intersectional analysis. This type of analysis not only attends to gender, but also to other intersecting aspects of an individual's social and political identity that positions them in the interstices of power oppression. As Armstrong, Gleckman-Krut, and Johnson (2018, p. 99) note, "sexual violence reproduces inequalities of gender, race/ethnicity, class, age, sexuality, ability status, citizenship, and nationality." As such, more research on the harms of nonconsensual intimate image dissemination, particularly that which is nuanced by an intersectional analysis, will provide insight into the types of solutions and best service provision practices required in order to not replicate the silencing and narrow focus "by some antisexual violence activism [that] fails women of color and other marginalized groups" (Armstrong et al., 2018, p. 99).

\section{Conclusion}

Relying on Mayer-Schönberger's (2009) concept of "permanent remembering," this chapter explored professionals' perspectives and understandings of the additive role that technology plays in the harms and impacts of sexual violence. The nonconsensual dissemination of intimate images and videos acts as a digital "layer" operating in addition to the commission of physical acts of sexual violence. This serves to layer, or compound, the harms experienced by the victim by adding a virtual - and indelible - "permanent remembering" of the act of violence. Violence here is a broad term, which speaks to an array of contexts in which such images are produced and shared. This ranges from images that were initially shared within the confines of a consensual sexual exchange and then 
nonconsensually distributed to physically perpetrated sexual assaults that were recorded and distributed virtually; to a myriad of contexts in between, such as being manipulated or coerced to take or share images. In addition to providing therapeutic and/or practical supports to survivors of physical acts of sexual violence, the permanency of images, as well as the trauma associated with the "threat" that images/videos can be released at any time in the future without warning, becomes part of the crisis that frontline professionals must also address.

Given that definitions of consent are central in legal determinations of sexual violence, and educational and awareness campaigns are focused on ongoing and enthusiastic positive consent as evinced by the slogan "yes means yes," nuancing the contours of consent in a technological context is of great importance. The ways in which digital and other technologies are used in sexual relationships; the additive role of, and considerations surrounding, navigating technology in sexual consent decision-making; the digital layering of harms; and the risks of digital "permanent remembering" must be attended to in educational and awareness contexts, in support and service practices, but also within the legal and criminal context. The harms of nonconsensual intimate image dissemination can be conceptualized under many frameworks, including cyberbullying (e.g., blackmail, humiliation, extortion, threat), privacy violation, criminal code infractions, and socio-legal analysis. However, as McGlynn et al. (2017) caution, we must be attentive to the uneven gendered scope, impacts, and consequences of sexual violence.

When looking to potential solutions, we must ensure that we recognize the normative discourses embedded in our understandings of sex, sexual conduct, and sexed gender roles and interactions. That the colloquialism "revenge pornography," for instance, is frequently used suggests an uncritical reflection to the ways in which the vocabularies of women's sexuality and women's sexual conduct are framed by patriarchal, heteronormative, and phallocentric narratives of gender, gender roles, sex, and sexual conduct. That nonconsensual nude images of women are referred to as revenge pornography suggests that women's nude bodies are always pornographic, and that the central issue of concern is the nudity or sex (e.g., leading to questions of why women took and shared the images in the first place) - and not the actual acts of harm and violence perpetrated (e.g., the violation of sexual privacy, trust, and engaging in sexual conduct without consent). This in turn leads to, for instance, calls for digital abstinence, and subsequent risk management strategies that serve to curtail or constrain the sexual conduct of individuals (generally teenage girls and women), responsibilizing individuals for the initial image-making, and centralizing the images themselves as problematic or the harm. As Mayer-Schönberger (2009) suggests, digital abstinence is virtually incongruent with how technology is embedded in our everyday lives, both professionally and personally. When thinking through the necessary support strategies and services available to victims of this type of sexual violence, as well as the ways that we legislate technologically facilitated sexual violence, we must unravel the complex ways that technology and digital spaces reveal the manifold layers of consent and the narratives or discourses embedded in our education, awareness, policing, or law-making. 


\section{Notes}

1. Although the website was stated to have been shut down in April 2018, it is currently operational, with new posts as of May 2020. In addition, an archive of images dated from 2018 and 2019 still remains on the website. Given that there is no indication that consent was obtained prior to the images being shared online, the website name will not be publicized in this chapter.

2. The website now indicates that it is "an adult image board where anyone can share porn images and write comments anonymously." It also has posted four rules: "1. Do not post any images containing minors, or questionable content that may contain minors under the age of 18! (This includes nonnude images); 2. Do not post or request personal information ('dox'); 3. The posting of any external links (URLs) is strictly forbidden, this also includes private trading (giving out your user id for offsite contact); 4. You will not upload, post, discuss, request, or link to anything that violates international law."

3. The research was approved by the Research Ethics Board at Ontario Tech University in Ontario, Canada, REB \#15000.

4. \#cancelculture is a variant of \#calloutculture. They are both a form of online shaming and describe a boycott - or a call to boycott - someone who has shared a controversial or offensive opinion or has engaged in behavior that is controversial or questioned. As Romano (2019) explains: "A celebrity or other public figure does or says something offensive. A public backlash, often fueled by politically progressive social media, ensues. Then comes the calls to cancel the person - that is, to effectively end their career or revoke their cultural cachet, whether through boycotts of their work or disciplinary action from an employer."

5. In 2010, while Melissa Petro was working as a public school teacher in New York, she was outed by the New York Post as a former sex worker. Petro herself had written a column for Huffington Post about her experiences selling sexual services through the "erotic services" section of Craigslist.com, an online classifieds site. She was forced to resign, not after her initial column, but after other newspapers started reporting on her, calling her "stripper teaching" in headlines. Parents and commentators remarked on her lack of "morals," "values," and "decency" required of the "higher" standards that are expected of teachers and questioned her ability to be a "role model" and her "suitability" to work with children.

\section{References}

Allen, B. (2019). Revenge porn and sext crimes: Canada sees more than 5,000 police cases as law marks 5 years. CBC News. Retrieved from https://www.cbc.ca/news/ canada/saskatchewan/reveng-porn-and-sext-crimes-canada-sees-more-than-5-000police-cases-as-law-marks-5-years-1.5405118

Armstrong, E. A., Gleckman-Krut, M., \& Johnson, L. (2018). Silence, power, and inequality: An intersectional approach to sexual violence. Annual Review of Sociology, 44, 99-122.

Bailey, J. (2015). A perfect storm: How the online environment, social norms, and law shapes girls' lives. In J. Bailey \& V. Steeves (Eds.), eGirls, eCitizens: Putting technology, theory and policy into dialogue with girls' and young women's voices (pp. 21-53). Ottawa, ON: University of Ottawa Press. 
Bates, S. (2017). Revenge porn and mental health: A qualitative analysis of the mental health effects of revenge porn on female survivors. Feminist Criminology, 12(1), $22-42$.

Beres, M. A., Crow, B., \& Gotell, L. (2009). The perils of institutionalization in neoliberal times: Results of a national survey of Canadian sexual assault and rape crisis centres. Canadian Journal of Sociology, 34(1), 135-163.

Bloom, S. (2014). No vengeance for 'revenge porn' victims: Unraveling why this latest female-centric, intimate-partner offence is still legal, and why we should criminalize it. Fordham Urban Law Journal, 42, 233-289.

Branch, K., Hilinski-Rosick, C., Johnson, E., \& Solano, G. (2017). Revenge porn victimization of college students in the United States: An exploratory analysis. International Journal of Cyber Criminology, 11(1), 128-142.

Burgin, R., \& Flynn, A. (2019). Women's behavior as implied consent: Male "reasonableness" in Australian rape law. Criminology and Criminal Justice. doi: $10.1177 / 1748895819880953$

Burkell, J. A. (2016). Remembering me: Big data, individual identity, and the psychological necessity of forgetting. Ethics and Information Technology, 18(1), 17-23.

Campbell, R. (2006). Rape survivors' experiences with the legal and medical systems. Do rape victim advocates male a difference?. Violence Against Women, 12(1), 30-45.

Chon, D. S. (2014). Policing reporting by sexual assault victims in Western and nonWestern countries. Journal of Family Violence, 29(8), 859-868.

Eaton, A. A., Jacobs, H., \& Ruvalcaba, Y. (2018). 2017 nationwide online study of non-consensual porn victimization and perpetration: A summary report. Retrieved from https://www.cybercivilrights.org/

Edwards, K. M., Turchik, J. A., Dardis, C. M., Reynolds, N., \& Gidycz, C. A. (2011). Rape myths: History, individual and institutional-level presence, and implications for change. Sex Roles, 65, 761-773.

Ehlers, A., \& Clark, D. M. (2000). A cognitive model of posttraumatic stress disorder. Behaviour Research and Therapy, 38, 319-345.

Fairbairn, J. (2015). Rape threats and revenge porn: Defining sexual violence in the digital age. In J. Bailey, \& V. Steeves (Eds.), eGirls, eCitizens: Putting technology, theory and policy into dialogue with girls' and young women's voices. (pp. 229-252). Ottawa, ON: University of Ottawa Press.

Flynn, A. (2015). Sexual violence and innovative responses to justice: Interrupting the recognisable narratives. In A. Powell, N. Henry, \& A. Flynn (Eds.), Rape justice: Beyond the criminal law (pp. 92-111). Basingstoke: Palgrave Macmillan.

Flynn, A., \& Henry, N. (2019). Image-based sexual abuse: An Australian reflection. Women and Criminal Justice. doi:10.1080/08974454.2019.1646190

Government of Canada. (2015). Protecting Canadians from Online Crime Act. Department of Justice. Retrieved from https:/www.canada.ca/en/news/archive/ 2015/04/protecting-canadians-online-crime-act-.html

Green, D. (2018, February 20). Revenge porn sites targets Canadian university students. The Phoenix. Retrieved from http://www.thephoenixnews.com/2018/02/ revenge-porn-site-targets-canadian-university-students/ 
Henry, N., Flynn, A., \& Powell, A. (2018). Policing image-based sexual abuse: Stakeholder perspectives. Police Practice and Research: An International Journal, 19(6), 565-581.

Henry, N., Flynn, A., \& Powell, A. (2019). Responding to revenge pornography: The scope, nature and impact of Australian criminal laws: A report to the criminology research council. Canberra, ACT: Australian Institute of Criminology.

Henry, N., McGlynn, C., Flynn, A., Johnson, K., Powell, A., \& Scott, A. J. (2020). Image-based sexual abuse: A study on the causes and consequences of non-consensual nude or sexual imagery. London and New York, NY: Routledge.

Humphreys, T. (2007). Perceptions of sexual consent: The impact of relationship history and gender. The Journal of Sex Research, 44(4), 307-315.

Karaian, L. (2014). Policing 'sexting': Responsibilization, respectability and sexual subjectivity in child protection/crime prevention responses to teenager' digital sexual expression. Theoretical Criminology, 18(3), 282-299.

Lee, M., \& Crofts, T. (2015). Gender, pressure, coercion and pleasure: Untangling motivations for sexting between young people. British Journal of Criminology, 55, $454-473$.

Liptak, A. (2018, April 29). Dutch police have shut down Anon-IB in the course of a revenge porn investigation. The Verge. Retrieved from https://www.theverge.com/ 2018/4/29/17299020/anon-ib-the-netherlands-dutch-police-revenge-porn-shut-down

Marques, O., \& Rinaldi, J. (2020, July). The politics of consent and the problem with focusing on violence. In G. C. Becker, \& A. T. Dionne (Eds.), Rape culture 101: Programming change (pp. 128-147). Brantford, ON: Demeter.

Mayer-Schönberger, V. (2009). Delete: The virtue of forgetting in the digital age. Princeton, NJ: Princeton University Press.

McArdle, M. (2019, August 13). The problem with making 'yes means yes' the standard for sexual assault. The Washington Post. Retrieved from https://www. washingtonpost.com/opinions/why-rape-laws-have-historically-relied-on-no-meansno-not-yes-means-yes/2019/08/13/cfeff8de-be0f-11e9-a5c6-1e74f7ec4a93_story.html

McGlynn, C., Rackley, E., \& Houghton, R. (2017). Beyond 'revenge porn': The continuum of image-based sexual abuse. Feminist Legal Studies, 25(1), 25-46.

McGlynn, C., Rackley, E., Johnson, K., Henry, N., Gavey, N., Flynn, A., \& Powell, A. (2020). "It's torture for the soul: The harms of image-based sexual abuse". Social \& Legal Studies, online first, doi:10.1177/0964663920947791

McGlynn, C., Rackley, E., Johnson, K., Henry, N., Flynn, A., Powell, A., ... Scott, A. (2019). Shattering lives and myths: A report on image-based sexual abuse. Retrieved from https://claremcglynn.files.wordpress.com/2019/06/shattering-livesand-myths-final.pdf

Office of the Privacy Commissioner of Canada. (2018, May). Guidelines for obtaining meaningful consent. Retrieved from https://www.priv.gc.ca/en/privacy-topics/collecting-personal-information/consent/g1_omc_201805/\#_seven

O’Sullivan, E., \& Carlton, A. (2001). Victim services, community outreach, and contemporary rape crisis centres: A comparison of independent and multiservice centres. Journal of Interpersonal Violence, 16(4), 343-360.

Patterson, D., Greeson, M., \& Campbell, R. (2009). Understanding rape survivors' decisions not to seek social systems help. Health \& Social Work, 34(2), 127-136.

Penney, R. (2016). The rhetoric of the mistake in adult narratives of youth sexuality: The case of Amanda Todd. Feminist Media Studies, 16(4), 710-725. 
Petro, M. (2017). The "hooker teacher" tells all. In D. M. Halperin \& T. Hoppe (Eds.), The war on sex (pp. 291-296). London: Duke University Press.

Powell, A., \& Henry, N. (2017). Sexual violence in a digital age. London: Palgrave Macmillan.

Powell, A., Henry, N., \& Flynn, A. (2018). Image-based sexual abuse. In W. S. DeKeseredy \& M. Dragiewicz (Eds.), Routledge handbook of critical criminology (2nd ed., pp. 305-315). Abingdon and New York, NY: Routledge.

Powell, A., Henry, N., Flynn, A., \& Henderson, E. (2013). Meanings of "Sex" and "Consent" and the Impact of Rape Law Reform in Victoria, Australia. Griffith Law Review, 22(2), 456-480.

Powell, A., Henry, N., Flynn, A., \& Scott, A. J. (2019). Image-based sexual abuse: The extent, nature, and predictors of perpetration in a community sample of Australian adults. Computers in Human Behavior, 92, 393-402.

Powell, A., Scott, A. J., Flynn, A., \& Henry, N. (2020). Image-based sexual abuse: An international study of victims and perpetrators. Summary report. Melbourne, VIC: RMIT University.

Romano, A. (2019, December 30). Why we can't stop fighting about cancel culture. Vox. Retrieved from https:/www.vox.com/culture/2019/12/30/20879720/what-iscancel-culture-explained-history-debate

RSC. (1985, c C-46). Canadian criminal code.

Rushowy, K. (2020, February 18). Ontario's rape crisis centres worry additional funding won't continue beyond March. Toronto Star. Retrieved from https:// www.thestar.com/politics/provincial/2020/02/18/ontarios-rape-crisis-centres-worryadditional-funding-wont-continue-beyond-march.html

Sable, M. R., Danis, F., Mauzy, D. L., \& Gallagher, S. K. (2006). Barriers to reporting sexual assault for women and men: Perspectives of college students. Journal of American College Health, 55(3), 157-162.

Slane, A. (2013). Sexing and the law in Canada. The Canadian Journal of Human Sexuality, 22, 117-122.

Slane, A., \& Langlois, G. (2018). Debunking the myth of 'not my bad': Sexual images, consent, and online host responsibilities in Canada. Canadian Journal of Women and the Law, 30(1), 42-81.

Starr, T. S., \& Lavis, T. (2018). Perceptions of revenge pornography and victim blame. International Journal of Cyber Criminology, 12(2), 427-438.

Walker, K., \& Sleath, E. (2017). A systematic review of the current knowledge regarding revenge pornography and non-consensual sharing of sexually explicit media. Aggression and Violent Behavior, 36, 9-24.

Wolak, J., Finkelhor, D., Walsh, W., \& Treitman, L. (2018). Sextortion of minors: Characteristics and dynamics. Journal of Adolescent Health, 62, 72-79. 